\title{
Product Evaluation Attributes and Consumer Product Trust of Branded and Generic Drugs: A Comparative Study of the United States and Kenya
}

\author{
Jackson Musyimi $^{1} \&$ Verna Omanwa ${ }^{2}$ \\ ${ }^{1}$ College of Business Administration, Daytona State College, Daytona Beach, Florida, USA \\ ${ }^{2}$ School of Business, Warner University, Lake Wales, Florida, USA \\ Correspondence: Jackson Musyimi, College of Business Administration, Daytona State University, 1200 W. \\ International Speedway Blvd. Daytona Beach, FL 32114, USA. Tel: 1-386-506-3261. E-mail: \\ Musyimj@daytonastate.edu
}

\author{
Received: May 10, $2014 \quad$ Accepted: June 3, $2014 \quad$ Online Published: July 28, 2014 \\ doi:10.5539/ijms.v6n4p1 URL: http://dx.doi.org/10.5539/ijms.v6n4p1
}

\begin{abstract}
A focus on understanding the attributes that impact product evaluation is important in developing effective marketing strategies of branded and generic drugs. This Quantitative cross-cultural study examines whether a relationship exists between product evaluation attributes and consumer product trust and loyalty of branded and generic drugs. This study examined the attributes of gender, country, product involvement, and consumer knowledge.A self-administered questionnaire was utilized to collect data from patients and employees from two different healthcare centers, one in Kenya and the other in central Florida. The outcome of the study indicated that there was a correlationbetween several of these attributes and consumer product trust of generic and branded drugs. Implications and limitations of this study are discussed. Despite of its limitations, the results of this study lay down a strong foundation for further research on this subject.
\end{abstract}

Keywords: consumer product trust, brand loyalty, product evaluation, product involvement, branded drugs, generic drugs, culture, Kenya, United States

\section{Introduction}

Prescription drugs sales is vital to pharmaceutical firms who use part of the proceeds to invest in sales and marketing and most importantly, in Research and Development (R\&D) of new drugs. The success of this industry depends on the success of its innovation. According to Cardinal (2001), "the pharmaceutical industry spends more as a percentage of sales and research on development than any other high-tech industry, including electronics, computers and aerospace" (p. 2).

It is thus important to understand consumers' evaluation of branded and generic drugs as this will assist pharmaceutical firms channel their resources to the appropriate areas with the highest potential for return on investment. Additionally, due to the global focus adapted by the pharmaceutical companies, it is imperative for them to understand consumers' cultural differences when developing branded drug loyalty.

Product evaluation is not only tied to the product functions or features but also to a variety of other factors. Factors such as social, economic and cultural can impact how consumers evaluate products (Souiden, Kassim, \& Heung-Ja, 2006). There is also strong evidence to suggest that product involvement is a major determinant of customer loyalty and trust (Iwasaki \& Havitz, 1998). The central premise of this argument is that customers with a high product involvement tend to be more attached and trustful to the product, hence more loyal to the brand. This premise however might differ among different cultures. Doney, Cannon and Mullen (1998) state that, "cultural norms and values facilitate or inhibit the formation of trust" (p. 2). For example in brand or product loyalty, members of different national cultures are likely to make purchasing decisions differently depending on their levels of loyalty and trust that are based on their cultural values (Yoo, 2009). Due to limited amount of cross-cultural research in this subject, this study will attempt to find if culture as a product evaluation attribute influences consumer product trust and loyalty of generic and branded drugs. The attributes of gender, product involvement and consumer knowledge will also be studied. 


\section{Literature Review and Hypothesis}

\subsection{Brand Loyalty and Trust}

Loyalty is the attachment to a brand due to favorable attitudes towards it mainly based on past experiences (Zhang, Dixit, \& Friedmann, 2010). This habitual attachment could be a result of the brand satisfying or meeting unique needs that the consumer seeks or the brand fitting the personality or self-image of the consumer. Also, the habitual attachment could be due to lack of knowledge, information and time in evaluating alternative brands, therefore most likely, the decision to purchase a particular brand would be based on convenience as the consumer's decision making process is simplified (Quester \& Lim, 2003). Marketers are realizing the importance of making positive first impression on consumers because it increases the likelihood of habitual purchases and loyalty. Additionally, it minimizes brand switching based on price since the preference is driven mostly on perceived quality of the brand (Chaudhuri \& Holbrook, 2001).

The underling argument is that increased market share influences brand loyalty through exposure. Empirical research has also shown that high share brands have more frequent repeat purchasers. In other words, consumers tend to buy these brands more often and at a regular frequency than brands with a low share (Fader \& Schmittlein, 1993). This is especially evident with niche brands such as newly approved branded drugs with no generic competition.

In addition to loyalty, trust also plays a large role in consumer perception of products. The classic view of the trust definition, according to Rotters (1971) is "a generalized expectancy held by an individual or group that the word, promise, verbal, or written statement of another individual or group can be relied on" (p. 444). Additional definition of brand trust by Delgado-Ballester (2003) is "Feeling of security held by the consumer in his/her interaction with the brand, that it is based on the perceptions that the brand is reliable and responsible for the interests and welfare of the consumer" (p.11).

Drawing from these definitions, competence, confidence and reliability are key factors to trust in that the trusting party fully expects the brand or product to perform as promised in a manner that will result in a positive outcome. All facets of brand loyalty and trust center on two purchasing approaches, behavioral and attitudinal approach (Quester \& Lim, 2003).

\subsection{Behavioral Approach}

VonRiesen, Herndon and VonRiesen (2001) state that, behavioral or operational purchasing pattern is whereby a consumer purchases a brand consistently for at least four consecutive times. Some researches have put forth several arguments to attest that behavioral purchasing patterns are vital to marketers. This includes patterns that can be measured and observed. The downside of this approach is that, since it is based on habit or overt purchase behavior, it can easily be disrupted if there is change in the purchase routine (Gentry \& Kalliny, 2008). This can occur when for example, a better deal from a competing brand such as generic drug is offered at a significantly lower price.

The non-attachment of a brand to the consumer belief system leads to spurious loyalty, which can be misleading to marketers (Quester \& Lim, 2003). Additional opinions point to the fact that, behavioral loyalty can be as a result of lack of choices as in cases of monopolistic settings like in pharmaceutical industry where a branded patent protected drug compels consumers to be loyal to it because of non existent of generic competitor drug (Gentry \& Kalliny, 2008). The convenience and resistance to change according to Gentry and Kalliny (2008) is also an important antecedent to behavioral loyalty especially where the cost of switching brands is greater than the cost of keeping the existing brand.

\subsection{Attitudinal Approach}

Many researches have evaluated brand loyalty and trust and concluded that it extends beyond repetitive purchases of a specific brand. A comprehensive understanding of brand loyalty and trust therefore should involve the consumer's psychological attachment towards a brand (Quester \& Lim, 2003). In his widely published article, Jacoby (1971) proposes that attitude behavior should incorporate affective, cognitive or conative component to highlight the correlation that exists between the three components. In other words, a change of one component will most likely affect the other components; hence a comprehensive measure of attitude brand loyalty and trust should include all three components.

Also, there is less likelihood of brand switching because the consumers are emotionally and psychologically attached to the brand. This aspect should provide the company reliable revenue stream as they have the luxury of charging premium prices for their products. Having a comprehensive understanding of the consumer repeat purchasing patronage would offer greater significance and provide marketers with long-term customer retention 
strategies (Chaudhuri \& Holbrook, 2001).

The importance of attitude loyalty and trust is that it is closely tied to consumer's willingness to pay premium prices, which are directly influenced by product. Customer based brand equity which includes repeat purchases of a specific brand on a consistent pattern leads to favorable attitudes towards the brand, which is used by the organization to compare the brand with other variables such as price and market share (Chaudhuri \& Holbrook, 2001).

\subsection{Product Involvement}

There is strong evidence to suggest that product involvement is a major determinant of customer loyalty and trust (Iwasaki \& Havitz, 1998). The central premise of this argument is that customers with a high product involvement tend to be more attached and committed to the product, hence more loyal to the brand. It is however important to distinguish between low and high involvement with a product in relation to repeat purchases. Quester and Lim (2003) state that repeat purchases on high involvement products leads to brand loyalty while repeat purchases with low involvement products are simply a habitual purchase. Iwasaki and Havitz (1998) further argue that, there is a chronological process that individuals go through to become loyal customers. In reference to pharmaceutical industry, high involvement patients are more likely to ask their Health Care Practitioner (HCP) about a drug in response to a Direct to Consumer Advertisement (DTCA) than a low involvement patient (Limbu \& Torres, 2009).

Social situational factors such as cultural norms and religion can influence one's involvement or attachment to a brand. Therefore, the stronger the psychological attachment consumers have to a certain brand, the more loyal they are likely to be because the brand product is perceived by the consumer as meeting emotional goals and values. In sum, brand involvement is greatly influenced by the consumer value system (McWilliams, 1997). Conversely, brand commitment or loyalty is lessened by low involvement with peripheral products that don't identify with a consumer's identity.

McWilliams (1997) lists several conditions associated with involvement; "perceived risk (financial, physical, psycho-social, or time-generated risk), the expression of one's own personality or mood (usually referred to as value-expressiveness or self-concept), the perceived importance and the hedonic value of the stimulus or object" (p. 2). Also, there is less likelihood of brand switching because the consumers are emotionally and psychologically attached to the brand. This aspect should provide the company reliable revenue stream as they have the luxury of charging premium prices for their products. Effective branding strategies should thereby offer a comprehensive understanding of the consumer repeat purchasing patronage and provide marketers with long-term customer retention strategies (Chaudhuri \& Holbrook, 2001). Based on these assumptions the following hypothesis is formulated:

Hypothesis 1: There is a relationship between drug choice involvement and consumer product trust in evaluation of branded and generic drugs.

\subsection{Country}

In a cross-cultural context, consumer behavior is influenced by culture (Nam, 2009). The new emerging global market and integration makes it important to learn and understand how culture especially national culture influences elements of consumer behavior such as trust (Doney, Cannon, \& Mullen, 1998). Hofstede (1980) states that cultural norms affect the development of trust. Several researchers have offered multiple definitions of culture, but the most adapted cultural definitions is that of Hofstede (1984) who defines culture as "the collective programming of the mind which distinguishes the members of one group from another" (p. 21). Culture taxonomies can therefore be used to understand factors that facilitate or inhibit cognitive trust building processes, and their impact on trust development (Doney, Cannon, \& Mullen, 1998).

Hofstede's cultural dimension of Individualism-Collectivism (IDV) is especially relevant to the issue of trust, in that consumers from individualistic cultures show more independence than those from collectivist consumers who show more interdependence and dependence (Yoo, 2009). Hofstede ranked Kenya a more collectivist country and the United States a more individualistic country.

While the adaptation of Individualism and Collectivism (IDV) is of paramount importance in cultural settings involving brand trust and perception, the relationship between uncertainty avoidance (UA) and evaluation of product uncertainty cannot be overlooked. Lee, Garbarino and Lerman (2007) quoting Hofstede defines UA as "extent to which the members of a culture feel threatened by uncertain or unknown situations" (p. 3) Hofstede (2001) adds "individuals in high UA cultures exhibit a lower tolerance for ambiguity and diversity than those in low UA cultures" (p. 3). Hofstede ranked Kenya a high uncertainty avoidance culture and the United States, low 
uncertainty avoidance culture (Hofstede, 2001). Based on these assumptions the following hypothesis is formulated:

Hypothesis 2: There is a relationship between country and consumer product trust in evaluation of branded and generic drugs.

\subsection{Gender}

Demographic factors and socioeconomic conditions such as income affect how consumers evaluate products. For example, in an expanding economy, consumers tend to focus on extrinsic product attributes like image and brand names while in a depressed economy, consumers are likely to focus on the price, features and performance attributes of the product (Samiee, Shimp, \& Sharma, 2005). Consumer behavior research has cited gender among attributes that impact product choice and evaluation. In a study carried out by Sahay et al. (2012) examining the role of gender differences on consumer brand relationships, revealed that women when asked about their choice of product showed that choices were mostly based on greater emotional experience while men evaluated such products using greater factual experience. In his seminal work, Hofstede (2001) discussed the dimension of masculinity and femininity. He argued that women tend to be more nurturing while men are more assertive. Study by Kolyesnikova et al. (2009) examined gender as a moderator of consumer behavior revealed that the dimension of femininity is greatly associated with emotional concern of others than masculinity. Based on these assumptions the following hypothesis is formulated:

Hypothesis 3: There is a relationship between gender and consumer product trust in evaluation of branded and generic drugs.

\subsection{Consumer Knowledge}

Consumer knowledge has been described as the familiarity and experience an individual has with a product (Kolyesnikova et al., 2009). Consumer knowledge is acquired from various sources including the Internet, advertising and from HCPs (DeLorme, Huh, \& Reid, 2007). According to Wirtz and Mattila (2003), consumer choice and behavior can be influenced by the amount of knowledge a consumer has on a particular product. In a state of information processing, consumers will choose products among several alternatives and eventually make their purchase selection from the most acceptable alternatives. Consumer knowledge also is influenced by culture, for example, in an individualistic country such as the United States, consumers are likely to share their loyalty among several brands especially in an environment with similar "me too" brands (Ramrattan \& Szneberg, 2006). Wirtz and Matilla (2003) acknowledge that consumers with higher product knowledge are able to make more informed choices, which increases brand loyalty and trust.

Level of a consumer's education can also influence the ability of a consumer to evaluate the product and make an educated judgment when choosing a product. The assumption is that consumers with higher levels of education will pay more attention to the quality and functional aspects of the product by taking additional steps to investigate the product. A study conducted by Creusen (2010) showed that individuals with lower education find functionalities of the product more important while those with higher education stress the importance of quality. "A tentative explanation might be that education leads to more informed judgments so that quality for some products can be better assessed, leading to a more important role of quality in the purchase decision" (Creusen, 2010, p. 28). Consumers view branded drugs to be more effective, high quality with low side effects compared to generics. The overall consensus is that generics are inferior with severe adverse effects compared to branded drugs. Based on this assumption, the following hypothesis is formulated:

Hypothesis 4: There is a relationship between education level and consumer product trust in evaluation of branded and generic drugs.

\section{Methodology}

\subsection{Sample}

Sample in this study consisted of employees and patients from two different Healthcare centers, one located in Kenya and the other in Central Florida. For confidentiality reasons, these centers were not identified in the research. Permission was requested and granted to survey the participants. Probability sampling was utilized to avoid bias and to ensure all participants in the population had an equal chance of being selected (Buckingham \& Saunders, 2004).

Two hundred and fifty surveys were given to each healthcare center to be administered to employees and patients. A total of 290 surveys were completed, 132 representing 45.5\% from the United States healthcare center and 158 representing 54.5\% from Kenyan healthcare center.Of the total surveys returned, 23 were 
incomplete thus unusable. Therefore, 267 surveys, 122 from the United States healthcare center and 145 from Kenyan healthcare center representing a combined total of $53.4 \%$ of the surveys distributed were used in the study.

\subsection{Measures}

The survey instrument consisted of questions adapted to measure consumer product trust. Since the survey was conducted in Kenya and the United States, where words and concepts can have different meanings, interpretations and for reliability purposes, some terminology in the questionnaire was translated. For example, a term such as branded drug is commonly referred to as 'original drug' in Kenya. Definitions of generic drug and branded drug were included in the survey cover page.

Consumer product trust was measured using questions adapted to fit the branded and generic drugs context from Chaudhuri and Holbrook (2001) and Quester and Lim (2003) scales. The scale developed by Chaudhuri and Holbrook (2001) which measures brand trust, brand affect and brand loyalty has repeatedly been used in research and thus proven valid. Quester and Lim (2003) scale is also widely used in research and it measures attitudinal and behavioral brand loyalty and because of its repeated use, the two measures have strong face validity and reliabilities.

Additionally, Consumer product trust was measured using constructs of reliability and intentions as defined in a model for brand trust developed by Delgado-Ballester (2003). Reliability is assessed by the product's ability to satisfy consumer needs in terms of credibility, competence and performance, while intentions will be assessed by the products ability to meet consumers' interests in terms of dependability and benevolence (Luk \& Yip, 2008).

\section{Analysis and Results}

\subsection{Descriptive Statistics}

The characteristics of participants by gender are shown in table 1 . Total percentage of female participants was higher with $55.43 \%$ compared to $44.57 \%$ of male participants. Percentage of female participants was higher in the United States than in Kenya while the percentage of male participants was higher in Kenya than in the United States.

Table 1. Percentage of participants by gender

\begin{tabular}{llllll}
\hline & & & \multicolumn{2}{c}{ Country } & \multirow{2}{*}{ Total } \\
\cline { 3 - 6 } & & & United States & Kenya \\
\hline \multirow{2}{*}{ Gender } & Male & Percentage & 36.9 & 51.0 & 44.57 \\
\cline { 2 - 5 } & Female & Percentage & 63.1 & 49.0 & 55.43 \\
\hline Total & & Percentage & 100.0 & 100.0 & 100.0 \\
\hline
\end{tabular}

In all education categories, percentage of participants who indicated they have used both branded and generic drugs was higher compared to those who have used only generic, branded or neither. Table 2 shows that none of the participants with a master's degree or higher indicated they have used generic drugs only.

Table 2. Choice of drug by education level

\begin{tabular}{|c|c|c|c|c|c|c|c|}
\hline & & & Generic drugs & Branded drugs & $\begin{array}{l}\text { Generic and } \\
\text { Branded drugs }\end{array}$ & Neither & Total \\
\hline \multirow[t]{10}{*}{ Education } & Less than high school & Count & 5 & 3 & 22 & 10 & 40 \\
\hline & & $\%$ of Total & 1.9 & 1.1 & 8.2 & 3.7 & 15.0 \\
\hline & High school graduate & Count & 27 & 23 & 51 & 1 & 102 \\
\hline & & $\%$ of Total & 10.1 & 8.6 & 19.1 & .4 & 38.2 \\
\hline & Some college, no degree & Count & 19 & 21 & 43 & 1 & 84 \\
\hline & & $\%$ of Total & 7.1 & 7.9 & 16.1 & .4 & 31.5 \\
\hline & Associates or Bachelors & Count & 5 & 5 & 24 & 2 & 36 \\
\hline & degree & $\%$ of Total & 1.9 & 1.9 & 9.0 & .7 & 13.5 \\
\hline & Master's degree or advanced & Count & 0 & 1 & 4 & 0 & 5 \\
\hline & & $\%$ of Total & .0 & .4 & 1.5 & .0 & 1.9 \\
\hline \multirow[t]{2}{*}{ Total } & & Count & 56 & 53 & 144 & 14 & 267 \\
\hline & & $\%$ of Total & 21.0 & 19.9 & 53.9 & 5.2 & 100.0 \\
\hline
\end{tabular}


Participants were asked to indicate their choice of prescription drug. Table 3 shows $21 \%$ of total participants, $22.1 \%$ from the United States and 20\% from Kenya stated that have used generic drugs. $19.9 \%$ of total participants, $6.6 \%$ from the United States and 31\% from Kenya stated they have used branded drugs. 5.2\% of participants, $4.9 \%$ from the United States and 5.5\% from Kenya indicated that they have used neither drug. This implies that some other method of treatment other than the use of generic or branded drugs was used be these participants. The majority of total participants with $53.9 \%$ indicated that they have used both generic and branded drugs, with $66.4 \%$ from the United States and $43.4 \%$ from Kenya.

Table 3. Choice of drug by country

\begin{tabular}{|c|c|c|c|c|c|}
\hline & & & \multicolumn{2}{|l|}{ Country } & \multirow[t]{2}{*}{ Total } \\
\hline & & & United States & Kenya & \\
\hline \multirow[t]{8}{*}{ Drug choice } & Generic drugs & Count & 27 & 29 & 56 \\
\hline & & $\%$ within Country & 22.1 & 20.0 & 21.0 \\
\hline & Branded drugs & Count & 8 & 45 & 53 \\
\hline & & $\%$ within Country & 6.6 & 31.0 & 19.9 \\
\hline & Generic and Branded drugs & Count & 81 & 63 & 144 \\
\hline & & $\%$ within Country & 66.4 & 43.4 & 53.9 \\
\hline & Neither drug & Count & 6 & 8 & 14 \\
\hline & & $\%$ within Country & 4.9 & 5.5 & 5.2 \\
\hline \multirow[t]{2}{*}{ Total } & & Count & 122 & 145 & 267 \\
\hline & & $\%$ within Country & 100.0 & 100.0 & 100.0 \\
\hline
\end{tabular}

\subsection{Drug Choice Involvement and Consumer Product Trust}

A Pearson coefficient was calculated for the relationship between drug choice and consumer product factors. Consumer product factor was measured using the constructs of brand loyalty, brand affect and brand trust. Table 4 shows a strong positive correlation was found for Brand loyalty $(r(265)=.177$, and sig=.004 or $\mathrm{p}<.001)$, Brand affect $(r(265)=.236$, and sig=.000 or $p<.001)$ and Brand Trust $(r(265)=.203$, and sig=.001 or $\mathrm{p}$ $<.001)$.

Table 4. Correlation between drug choice, education, country, gender and consumer product trust

\begin{tabular}{llllll}
\hline & & Drug Choice & Education & Country & Gender \\
\hline BRAND LOYALTY & Pearson Correlation & $.177^{* *}$ & -.065 & $.367^{* *}$ & $-.134^{*}$ \\
& Sig. (2-tailed) & .004 & .292 & .000 & .029 \\
& $\mathrm{~N}$ & 267 & 267 & 267 & 267 \\
\hline \multirow{2}{*}{ BRAND AFFECT } & Pearson Correlation & $.236^{* *}$ & -.057 & $.318^{* *}$ & -.100 \\
& Sig. (2-tailed) & .000 & .354 & .000 & .103 \\
& $\mathrm{~N}$ & 267 & 267 & 267 & 267 \\
\hline BRAND TRUST & Pearson Correlation & $.203^{* *}$ & -.050 & $.304^{* *}$ & $-.137^{*}$ \\
& Sig. (2-tailed) & .001 & .420 & .000 & .025 \\
& $\mathrm{~N}$ & 267 & 267 & 267 & 267 \\
\hline
\end{tabular}

Note. *. Correlation is significant at the 0.05 level (2-tailed)

\subsection{Education Level and Consumer Product Trust}

From table 4, a pearson coefficient calculated for the relationship between education and consumer product factors indicates a weak negativecorrelation that was not significant for Brand loyalty $(r(265)=-.057$, and sig=.354 or $p>.05)$, Brand affect $(r(265)=-.065$, and sig=.292 or $p>.05)$ and Brand Trust $(r(265)=-.050$, and sig $=.420$ or $p>.05$ ).

\subsection{Gender and Consumer Product Trust}

A Pearson coefficient calculated for the relationship between gender and consumer product factors as shown in table 5 shows a strong positive correlation was found for Brand loyalty $(r(265)=-.134$, and sig=.029 or $p<.05)$ and Brand trust $(r(265)=-.137$, and sig=.025 or $p<.05)$. No significant correlation was found for Brand affect $(r(265)=-.100$, and $\operatorname{sig}=.103$ or $p>.05)$. 


\subsection{Country and Consumer Product Trust}

A Pearson coefficient calculated for the relationship between country and consumer product factors. As indicated in table 4 shows a strong positive correlation was found for Brand loyalty $(r(265)=.367$, and sig $=.000$ or $p$ $<.001)$, Brand affect $(r(265)=.318$, and sig $=.000$ or $p<.001)$ and Brand Trust $(r(265)=.304$, and $\operatorname{sig}=.000$ $p<.001)$. These findings suggest that consumer product trust of generic and branded drugs is influenced by a participant's country of origin, which in this case is Kenya and the United States.

\section{Discussion and Implications}

Results from this study provide important implications for managers in the pharmaceutical industry in providing effective marketing strategies. Findings of a Pearson Correlation showed a strong relationship between drug choice and consumer product trust factors of brand loyalty, brand trust and brand affect. This finding is supported by literature that indicates consumers that have high involvement with a specific product tend to choose that particular product over other products. Kolyesnikova et al. (2009) state that, "product involvement may influence consumer reciprocal behavior" (p. 202). Hence, consumers that have involvement with a generic drug will choose this drug over the branded drug.

The findings suggest that there is a difference between genders as it relates to consumer product trust factors of brand loyalty and brand trust. Literature reviews on gender have found out that women and men differ on how they evaluate products. According to Sahay et al. (2012), these studies infer that males and females will display opposite levels of affect and cognition in their brand relationships. This underscores the importance of taking into account gender differences when targeting branded and generic drugs to consumers.

This study showed a negative relationship between education level and consumer product trust factors. Most studies on consumer knowledge measure this factor using subjective and objective knowledge rather than education level. Creusen (2010) defined subjective knowledge as what consumers think they know and objective knowledge as that factual knowledge a consumer has regarding a particular product. Researchers suggest that subjective knowledge is an appropriate predictor of how consumers evaluate and purchase a product (Creusen, 2010). Additionally other researches suggest that subjective knowledge is closely related to prior experiences (Creusen, 2010).

The results of this study suggest a difference in perception of product trust between Kenya and the United States consumers. These findings support literature on cultural differences between these two countries. Nam (2009) suggests that trust is influenced by culture and states that, "commonly held values can influence consumers' value judgments about product alternatives, which in turn affect choice criteria" (p. 3). The results of this study makes an important contribution to the subject of consumer product trust and lays down a foundation for the pharmaceutical industry in the marketing of their drugs to different cultural markets. Managers clearly benefit from the results that point out the relevance found for country on consumer product trust of generic and branded drugs, which therefore should enable them develop effective strategies to enhance perception of their products. This study compared Kenya and the United States, which have distinct cultures. According to Dooney, Cannon and Mullen (1998), culture is a major determinant of product loyalty and trust. Therefore, branding strategies should incorporate Kenya and the United States cultural ideologies, which are based on collectivism and individualism respectively.

\section{Limitations and Further Research}

The results of this study pertains to the countries studied, Kenya and the United States and should not be generalized to apply to other settings. This research has several limitations. First, this cross sectional study was limited to two rural Healthcare facilities representing similar demographic patterns. The sample size was relatively small which weakened the findings of the study. A much diverse larger sample of participants from hospitals located in urban areas could be used in further research to increase the validity of the study.

Exclusion of income variable was a limitation in this study as well. Income affects how consumers evaluate products especially in a recessionary economy where price is a major determinant of product purchase (Samiee, Shimp, \& Sharma, 2005). Therefore, a question asking respondents to indicate their income levels would have further strengthened the findings by examining the impact of income on drug choice.

The outcomes of the study were also influenced by specific characteristics such as branding strategies and how they are used in both countries. For example, while the United States allows DTCA, Kenya does not. This limits consumers' product exposure and brand awareness, which affects demonstration effect, therefore, a longitudinal study would be recommended to provide stronger inferences.

The independent variable in this study was measured by asking respondents of their drug choice. Future research 
could measure the variable of perception using the constructs of efficacy, safety and value from instruments such as those developed by Chauduri and Holbrook (2001) and Quester and Lim (2003).

\section{Conclusion}

This research examinedproduct trust and loyalty in relation to branded and generic drugs and factors that influence product evaluation. Paradoxically, the importance of understanding product evaluation attributesas well as understanding the different cultural dynamics between the United States and Kenya is a prerequisite for success as it enables the pharmaceutical firms to channel their resources to the appropriate areas with the highest potential for return on investment.

\section{References}

Buckingham, A., \& Saunders, P. (2004). The survey methods workbook: From design to analysis. New York: Polity Press.

Cardinal, L. (2001). Technological innovation in the pharmaceutical industry: the use of organizational control in managing Research and Development. Organization Science, 12(1). http://dx.doi.org/10.1287/orsc.12.1.19.10119

Chaudhuri, A., \& Holbrook, M. (2001). The Chain of Effects from Brand Trust and Brand Affect to Brand Performance: The Role of Brand Loyalty. Journal of Marketing, 65(2), 81-93. http://dx.doi.org/10.1509/jmkg.65.2.81.18255

Creusen, M. E. (2010). The importance of product aspects in choice: The influence of demographic characteristics. The Journal of Consumer Marketing, 27(1), 26-34. http://dx.doi.org/10.1108/07363761011012921

Delgado-Ballester, E. (2003). Development and validation of a brand trust scale. International Journal of Market Research, 45(1), 35-54.

DeLorme, D. E., Huh, J., \& Reid, L. N. (2007). Seniors' perceptions of prescription drug information sources. International Journal of Pharmaceutical and Healthcare Marketing, 1(2), 107-127. http://dx.doi.org/10.1108/17506120710762979

Doney, P., Cannon, J., \& Mullen, M. (1998). Understanding the influence of national culture on the development of trust. The Academy of Management Review, 23(3).

Fader, P., \& Schmittlein, D. (1993). Excess Behavioral Loyalty for High-Share Brands: Deviations from the Dirichlet Model For Repeat Purchasing. Journal of Marketing Research (JMR), 30(4), 478-493. http://dx.doi.org/10.2307/3172692

Gentry, L., \& Kalliny, M. (2008). Consumer Loyalty-A Synthesis, Conceptual Framework, and Research Propositions. Journal of American Academy of Business, Cambridge, 14(1), 1-9.

Hofstede, G. (1980). Culture's Consequences: International Differences in Work-related Values. Beverly Hills, Cal., and London: Sage.

Hofstede, G. (1984). Culture's Consequences: International Differences in Work-related Values. (Abridged ed.). Beverly Hills, CA: Sage.

Hofstede, G. (2001). Culture's Consequences: International Differences in Work-related Values (2nd ed.). Beverly Hills, CA: Sage.

Iwasaki, Y., \& Havitz, M. E. (1998). A path analytic model of the relationships between involvement, psychological commitment, and loyalty. Journal of Leisure Research, 30(2), 256-280.

Jacoby, J. (1971). A Model of Multi-Brand Loyalty. Journal of Advertising Research, 11(3), 25-31.

Kolyesnikova, N., Dodd, T. H., \& Wilcox, J. B. (2009). Gender as a moderator of reciprocal consumer behavior. The Journal of Consumer Marketing, 26(3), 200-213. http://dx.doi.org/10.1108/07363760910954136

Lee, J., Garbarino, E., \& Lerman, D. (2007). How cultural differences in uncertainty avoidance affect product $\begin{array}{llll}\text { perceptions. International } & \text { Marketing 330-349. }\end{array}$ http://dx.doi.org/10.1108/02651330710755320

Limbu, Y., \& Torres, I. (2009). The effects of involvement and Ad type on attitudes toward direct-to-consumer advertising of prescription drugs. Journal of Health and Human Services Administration, 32(1), 107-38.

Luk, S., \& Yip, L. (2008). The moderator effect of monetary sales promotion on the relationship between brand 
trust and purchase behaviour. Journal of Brand Managemen, 15(6), 452-464.

McWilliam, G. (1997). Low involvement brands: is the brand manager to blame? Marketing Intelligence \& Planning, 15(2), 60. http://dx.doi.org/10.1108/02634509710165867

Nam, S. (2009). Cultural Influence on Loyalty Behaviors. The Business Review, Cambridge, 12(2), 212-219.

Quester, P., \& Lim, A. L. (2003). Product involvement/brand loyalty: Is there a link? The Journal of Product and Brand Management, 12(1), 22-36. http://dx.doi.org/10.1108/10610420310463117

Ramrattan, L., \& Szneberg, M. (2006). Global competition and the United States pharmaceutical industry. American Economist, 50(2).

Rotter, J. (1971). Generalized expectancies for interpersonal trust. American Psychologist, 26(5), 443-452. http://dx.doi.org/10.1037/h0031464

Sahay, A., Sharma, N., \& Mehta, K. (2012). Role of affect and cognition in consumer brand relationship: Exploring gender differences. Journal of Indian Business Research, 4(1), 36-60. http://dx.doi.org/10.1108/17554191211206799

Samiee, S., Shimp, T., \& Sharma, S. (2005). Brand origin recognition accuracy: its antecedents and consumers' cognitive limitations. Journal of International Business Studies, $36(4), 379$. http://dx.doi.org/10.1057/palgrave.jibs. 8400145

Souiden, N., Kassim, N. M., \& Hong, H. J. (2006). The effect of corporate branding dimensions on consumers' product evaluation. European Journal of Marketing, 40(7), 825-845. http://dx.doi.org/10.1108/03090560610670016

VonRiesen, R., Herndon, J., \& VonRiesen, C. (2001). An Investigation of Attitude Toward the Brand, Commitment, and True Brand Loyalty in a Cross-Cultural Context. Journal of East-West Business, 7(1), 37. http://dx.doi.org/10.1300/J097v07n01_03

Wirtz, J., \& Mattila, A. (2003). The effects of consumer expertise on evoked set size and service loyalty. The Journal of Services Marketing, 17(6/7).

Yoo, B. (2009). Cross-national invariance of the effect of personal collectivistic orientation on brand loyalty and equity: The United States versus South Korean consumers. Asia Pacific Journal of Marketing and Logistics, 21(1), 41-57. http://dx.doi.org/10.1108/13555850910926236

Zhang, J., Dixit, A., \& Friedmann, R. (2010). Customer loyalty and lifetime value: An empirical investigation of consumer packaged goods. Journal of Marketing Theory \& Practice, 18(2), 127-139. http://dx.doi.org/10.2753/MTP1069-6679180202

\section{Copyrights}

Copyright for this article is retained by the author(s), with first publication rights granted to the journal.

This is an open-access article distributed under the terms and conditions of the Creative Commons Attribution license (http://creativecommons.org/licenses/by/3.0/). 